\title{
STUDI TEMPERATUR UDARA TERKINI DI WILAYAH DI JAWA TENGAH DAN DIY
}

\author{
Oleh: \\ Suhadi Purwantara \\ Jurusan Pendidikan Geografi FIS UNY \\ Suhadi_p@uny.ac.id
}

\begin{abstract}
Abstrak
Artikel ini dikembangkan dari penelitiaan dengan judul Studi Revisi Rumus Braak dan Mock tentang Gradien Suhu Udara di Jawa Tengah dan DIY" ini berawal dari hasil perhitungan gradien suhu udara menurut rumus Braak yang sudah tidak sesuai dengan fakta lapangan. Banyak wilayah pegunungan yang dulu relatif dingin sekarang sudah tidak dingin seperti dulu lagi. Masyarakat merasa temperatur udara semakin panas. Untuk itu dalam penelitian ini bertujuan untuk mengetahui suhu udara di permukaan air laut, perbedaan suhu udara per seratus meter hingga ketinggian 2000an meter, dan selisih hasil perhitungan dengan formula Braak dengan data di wilayah penelitian. Populasi dalam penelitian ini ad alah semua udara yang ada di wilayah permukaan bumi di Pulau Jawa bagian Tengah. Penelitian ini bersifat penelitian kuantitatif berdasarkan hasil pengukuran langsung dan perekaman data sekunder. Penelitian ini menggunakan instrumen thermometer, dan formulir isian data. Pengumpulan data sekunder diperoleh dari instansi-instansi yang terkait dengan masalah dan tujuan penelitian antara lain : data temperatur. Dalam penelitian ini analisis dilakukan dengan memasukkan hasil pengukuran primer yang dirata-rata kemudian dimasukkan dalam rumus Braak. Hasil penelitian menunjukkan perbedaan suhu udara berdasar perbedaan tinggi tempat masih mengikuti rumus Braak, hanya suhu udara di permukaan laut yang sering para peneliti menggunakan angka $26,3^{\circ} \mathrm{C}$, menjadi $28,5^{\circ} \mathrm{C}$. Temperatur udara berdasarkan data menunjukkan bahwa terjadi peningkatan yang sangat nyata. Wilayah pantai yang merupakan wakil permukaan air laut bersuhu udara bulan April Mei 2012 sebesar $28,5^{\circ} \mathrm{C}$, suhu udara pada $800 \mathrm{~m}$ sebesar $24^{\circ} \mathrm{C}$, dan suhu udara pada ketinggiaan udara 2100 meter sebesar $16,25^{\circ} \mathrm{C}$. Pada ketinggian 800 meter, perbedaan temperatur hasil perhitungan rumus Braak dengan data lapangan hanya $23,62{ }^{\circ} \mathrm{C}$ dengan $24{ }^{\circ} \mathrm{C}$, atau $1,2 \%$, sedangkan di wilayah dengaan ketinggian 2100 meter, perbedaan temperatur hasil perhitungan rumus Braak dengan data lapangan hanya $16,70{ }^{\circ} \mathrm{C}$ dengan $16,25{ }^{\circ} \mathrm{C}$, atau $2,1 \%$.
\end{abstract}

Kata kunci: temperature udara, gradien suhu

\section{PENDAHULUAN}

Pada beberapa dasa warsa terakhir semakin sering masyarakat pemerhati iklim memper-bincangkan fenomena El Nino dan La Nina. Diskusi tentang fenomena tersebut tidak jauh dengan percakapan tentang gejala perubahan iklim (climate changes). El Nino dan La Nina sendiri adalah adanya suatu fenomena penyimpangan atau anomali iklim, yaitu adanya perbedaan temperatur dan tekanan udara yang tidak normal. El Nino dalam bahasa Latin berarti si anak natal, sedangkan La Nina berarti si nona kecil. Diberi nama si anak natal (corrientes de niño), berawal dari ceritera nelayan Peru yang selalu kehilangan 
ikan pada setiap bebeapa tahun sekali di seputar hari Natal, karena tiba-tiba air laut menjadi lebih hangat daripada biasanya, sehingga tidak ada ikan yang bisa diambil (Strahler, 1987: 142).

Bagi masyarakat awam, terutama di Indonesia, perubahan iklim yang ada dapat dijumpai antara lain suhu udara yang semakin panas, pola hujan yang kurang menentu, dan semakin sering timbulnya badai. Pada tahun 2008 ketika Bengkulu diterjang badai dengan kekuatan hingga 120 km per jam, yang oleh BMG langsung dinamai Badai Durga, sangat mengejutkan masyarakat, karena sebenarnya di Indonesia badai tidak akan melintasi Indonesia. Indonesia hanya menerima dampak tidak langsung dari badai tersebut (Achmad Zakir, BMG). Dampak badai dari wilayah lain biasanya tidak lebih dari $100 \mathrm{~km} / \mathrm{jam}$. Itulah makanya terus harus ada penelitian-penelitian tentang iklim, karena itu berkaitan langsung dengan kehidupan manusia. Iklim memiliki banyak anasir, seperti suhu udara, kelembaban udara, tekanan udara, hujan, angina, radiasi matahari.

Salah satu anasir iklim tersebut di atas adalah suhu udara. Suhu udara mengalami penurunan secara gradasi. Menurut penelitian terdahulu, penurunan suhu udara sekitar 0,6 setiap kenaikan tinggi tempat 100 meter di permukaan bumi (Braak, 1977). Permasalahannya adalah banyak masyarakat berpendapat bahwa di wilayah pegunungan sudah tidak sedingin 30 tahun yang lalu. Apakah betul telah terjadi perubahan suhu udara? Apabila betul, apakah mungkin penurunan suhu udara sekarang sudah tidak mengikuti formula peneliti terdahulu? Untuk menjawab pertanyaan permasalahan tersebut berikut ini hasil penelitian tentang perubahan gradien suhu udara di wilayah Jawa Tengah dan Yogyakarta.

Penelitian ini bertujuan untuk mengetahui suhu udara di permukaan air laut, untuk mengetahui perbedaan suhu udara per seratus meter hingga ketinggian 2000an meter, untuk mengetahui selisih hasil perhitungan dengan formula Braak dengan data di wilayah penelitian.

\section{CUACA DAN IKLIM}

Weather is physical state of the atmosphere at a given time and place (Strahler, 1987: 524). Cuaca adalah keadaan udara dalam waktu sesaat, seperti ada tidaknya sinar matahari, awan, angin, dan hujan, dipelajari dalam meteorologi. Meteorologi adalah ilmu yang mempelajari gejala-gejala cuaca dalam ruang dan jangka waktu terbatas. Climate is the characteristic condition of the atmosphere near the earth's surface as a given place or over a given region (Strahler, 1987: 144). Iklim adalah keadaan udara dekat permukaan bumi di suatu wilayah tertentu, dipelajari dalam klimatologi. Klimatologi adalah ilmu pengetahuan yang mempelajari gejala-gejala cuaca secara umum dalam waktu yang lebih lama dan pada daerah yang relatif luas. Misalnya, wilayah Asia Tenggara yang terletak di daerah ekuator, memiliki iklim tropis yang salah satu cirinya memiliki intensitas curah hujan yang tinggi.

Pengamatan, pencatatan, dan analisis cuaca dan iklim di Indonesia dilakukan oleh Badan Meteorologi dan Geofisika (BMG). Pengamatan dan pencatatan keadaan cuaca tersebut meliputi suhu udara, arah angin, kecepatan angin, kelembapan udara, awan, dan curah hujan. Hasilnya digunakan sebagai bahan analisis keadaan cuaca ataupun iklim di Indonesia. 


\section{UNSUR-UNSUR CUACA DAN IKLIM}

Unsur-unsur cuaca dan iklim meliputi suhu udara, kelembapan cuaca, tekanan udara, angin, awan, dan curah hujan.

\section{a. Suhu udara}

Matahari merupakan salah satu sumber panas bagi permukaan bumi. Pancaran sinar matahari ke permukaan bumi menimbulkan adanya energi. Permukaan atmosfer menerima energi sebesar 1,94 kalori/menit setiap $\mathrm{cm}^{2}$ yang terdiri atas sinar ultraviolet, sinar inframerah, dan sinar cahaya. Hal inilah yang menyebabkan perbedaan suhu udara di permukaan bumi, yaitu banyak sedikitnya sinar matahari yang sampai di permukaan bumi.

Banyak sedikitnya sinar matahari yang sampai ke permukaan bumi tergantung pada sudut datang sinar matahari, semakin kecil sudut datang sinar, semakin banyak sinar matahari yang diterima bumi, lamanya penyinaran matahari, tebal tipisnya awan, ada tidaknya penghalang di permukaan bumi (rumah, vegetasi, dan sebagainya), jenis zat permukaan bumi yang disinari (daratan lebih cepat menerima panas daripada lautan).

Posisi Indonesia terletak di daerah khatulistiwa, sehingga memperoleh sinar matahari secara maksimal dan merata sepanjang tahun. Rata-rata suhu udara di Indonesia setiap tahunnya adalah $27^{\circ} \mathrm{C}$, untuk daratan rata-rata $28^{\circ} \mathrm{C}$ dan lautan sebesar $26,3^{\circ} \mathrm{C}$. Semua diukur di atas permukaan air laut. Untuk setiap kenaikan 100 meter pada suhu normal akan mengalami penurunan sebesar $0,60^{\circ} \mathrm{C}$, tetapi untuk udara kering suhu udara turun $1^{\circ} \mathrm{C}$.

Penentuan suhu rata-rata tahunan menggunakan data suhu udara harian. Pengukuran suhu udara dilakukan setiap hari selama 24 jam dicatat pada tiap jamnya. Hasil pengukuran ini digunakan untuk menentukan suhu rata-rata harian. Suhu ratarata harian digunakan untuk menentukan suhu rata-rata bulanan dan suhu rata-rata bulanan digunakan untuk menentukan suhu rata-rata tahunan.

Ketinggian suatu tempat yang ada di permukaan bumi berpengaruh terhadap tekanan udara dan suhu udara. Semakin tinggi tempat di permukaan bumi, semakin rendah suhu udaranya.

Menurut Braak:

$$
\left(0,61^{\circ} \mathrm{C}-\mathrm{h}\right)
$$

$\mathrm{t}=26,3^{\circ} \mathrm{C}$

100

Keterangan :

$\mathrm{t}=$ suhu udara

$26,3 \mathrm{C}=$ suhu rata-rata tahunan

$0,61 \mathrm{C}=$ gradien suhu setiap kenaikan $100 \mathrm{~m}$

$\mathrm{h}=$ ketinggian tempat

Formula yang lain adalah formula Mock. Menurut Mock, besarnya $t$ adalah sama dengan selisih tinggi tempat dikalikan dengan konstanta 0,006.

$\mathrm{t}=0,006(\mathrm{z} 1-\mathrm{z} 2)$

Z1 adalah tinggi tempat lokasi 1, Z2 adalah tinggi tempat lokasi 2 


\section{KERANGKA PENELITIAN}

Temperatur udara di permukaan bumi tidak seragam. Ketidaksamaan temperature udara sangat dipengaruhi oleh tinggi tempat. Semakin tinggi tempat di permukaan bumi maka temperature udara semakin rendah.Penelitian ini diawali dengan mencari data primer dan sekunder selama beberapa tahun, temperatur di berbagai tempat yang mewakili tempat di permukaan bumi. Hasil pengumpulan data temperatur udara berdasar ketinggian tersebut kemudian dimasukkan dalam rumus yang ada. Data yang dikumpulkan adalah data temperature di berbagai ketinggian yang berbeda, antara lain pada ketinggian 0 meter, 100 meter, 200 meter, 300 meter, 400 meter, hingga 2000an meter. Apakah formula masih sesuai, ataukah telah mengalami perubahan?

Tujuan akhir dari penelitian ini adalah mengevaluasi formula-formula yang telah ada tentang gradient penurunan temperature setiap penaikan tinggi tempat. Kemungkinanya adalah formula tetap sam, masih berlaku, ataukan formula telah berubah, dalam arti formula lama sudah tidak dapat diterapkan di wilayah Jawa, khususnya Jawa bagian Tengah.

Penelitian ini adalah penelitian murni yang hasilnya untuk kepentingan pembelajaran dan riset berikutnya bagi dosen maupun mahasiswa. Intinya adalah mengevaluasi konstante rumus yang telah ada, diambil dari penelitian ilmuwan Barat. Penelitian didasari dengan teori yang telah ada dan menggunakan hasil pengumpulan data primer. Data primer berupa suhu udara kemudian diterapkan pada rumus yang telah ada. Berdasarkan analisis akan diketahui bahwa rumus masih berlaku atau sama sekali sudah tidak berlaku untuk wilayah penelitian.

Lokasi dalam penelitian ini adalah sebagian wilayah pantai di DIY dan Jawa Tengah. Populasi dalam penelitian ini adalah semua udara yang ada di wilayah permukaan bumi di Pulau Jawa bagian Tengah. Penelitian ini bersifat penelitian kuantitatif berdasarkan hasil pengukuran langsung dan perekaman data sekunder. Penelitian kuantitatif yaitu suatu penelitian untuk memperoleh suatu data yang jelas pada suatu daerah atau kondisi obyek yang diteliti pada saat dilakukan penelitian.

Pendekatan Geografi yang digunakan dalam penelitian ini adalah pendekatan ekologi. Pendekatan ekologi merupakan pendekatan yang menekankan pada lingkungan hidup, interaksinya dengan manusia. Dalam hal ini wilayah Yogyakarta dan Jawa Tengah.

Kondisi udara yang dijadikan sample adalah suhu udara yang terukur dengan thermometer suhu udara, baik yang ada di stasiun-stasiun pengamat cuaca, stasiun hujan, maupun diukur langsung. Data suhu udara diambil dari wilayah Parangtritis, Kecamatan Kretek Bantul, mewakili ketinggian mendekati 0 meter, wilayah Wonosobo mewakili ketinggian mendekati 800 dan wilayah dataran tinggi Dieng mewakili ketinggian mendekati 2000an meter.

Penelitian ini menggunakan instrumen penelitian berupa thermometer, dan formulir isian data. Untuk mencapai tujuan penelitian maka data yang dikumpulkan, dibagi menjadi, dua yaitu data primer dan data sekunder. Data primer, atau data tangan pertama adalah data yang diperoleh secara langsung dari subjek penelitian. Data primer didapat dari pengukuran langsung dengan purposive random sampling. Pengumpulan data sekunder diperoleh dari instansi-instansi yang terkait dengan masalah dan tujuan penelitian antara lain : data temperatur. 
Dalam penelitian ini analisis dilakukan dengan memasukkan hasil pengukuran primer yang dirata-rata dengan pengkuran sekunder dan kemudian dimasukkan dalam rumus yang telah ada. Hasilnya dilaporkan dalam bentuk deskripsi hasil penelitian. Formula Braak:

$$
\left(0,61^{\circ} \mathrm{C}-\mathrm{h}\right)
$$

$\mathrm{t}=26,3^{\circ} \mathrm{C}$

$$
100
$$

Keterangan :

$\mathrm{t}=$ suhu udara

26,3 C = suhu rata-rata tahunan d.p.a.l.

$0,61 \mathrm{C}=$ gradien suhu setiap kenaikan $100 \mathrm{~m}$

$\mathrm{h}=$ ketinggian tempat

Formula yang lain adalah formula Mock:

$$
\mathrm{t}=0,006(\mathrm{z1}-\mathrm{z2})
$$

Keterangan :

t adalah sama dengan selisih tinggi

Z1 adalah tinggi tempat lokasi 1

Z2 adalah tinggi tempat lokasi 2

\section{HASIL PENELITIAN}

\section{Deskripsi Wilayah}

Wilayah penelitian adalah di Parangtritis Yogyakarta yang berada di garis pantai dengan ketinggian 0 meter hingga 15 meter, wilayah Wonosobo mewakili ketinggian mendekati 800 meter dan wilayah dataran tinggi Dieng mewakili ketinggian mendekati 2000an meter.

Parangtritis merupakan wilayah dataran pantai selatan di Kabupaten Bantul daerah Istimewa Yogyakarta. Sebelah timur dibatasi dengan perbukitan kapur, sebelah barat merupakan muara Sungai Opak. Kondisi geologis Parangtritis, berdasar peta geologi lembar Yogyakarta, Jawa, oleh Wartono Raharjo dkk (1977), terdapat tiga formasi batuan, yaitu aluvium (Qa), endapan vulkanik Merapi muda, dan formasi Nglanggran. Aluvium terdiri atas kerakal, pasir, lanau, dan lempung yang redapat di sepanjang Sungai Opak, dataran banjir, igir-igir pantai, dan bukit-bukit pasir. Endapan vulkanik Merapi muda terdiri atas aluvial yang berasal dari Merapi terdapat di wilayah bekas laguna. Formasi Nglanggran berupa brekssi vukanik breksi aliran, aglomerat, lava, dan tufa. Sebagian besar batuan tersebut telah lapuk menjadi tanah berwarna coklat kemerahan. Batuan tersebut tersebar di pegunungan Baturagung yang terbentang utara ke timur. Secara geomorfologis wilayah Parangtritis terdiri atas unit-unit geomorfik berupa kipas aluvial, dataran banjir, dataran bekas laguna, gumuk-gumuk pasir, dan pegunungan blok patahan.

Wilayah Wonosobo berada di Provinsi Jawa Tengah, berjarak $140 \mathrm{~km}$ dari Parangtritis. Wonosobo merupakan wilayah pegunungan. Ketinggian tempat berkisar 800 meter dpal. Dataran tinggi Dieng juga masih berada di wilayah Wonosobo, dengan ketinggian tempat 2100 meter dpal. Jarak wilayah Dieng ke Parangtritis 160 km. 
Berdasarkan data primer temperatur udara daerah penelitian seperti berikut.

Tabel 1. Suhu Udara di Berbagai Lokasi

\begin{tabular}{|l|l|l|}
\hline Lokasi & Ketinggian (meter) & Suhu C \\
\hline Parangtritis & 0 & 28,5 \\
\hline Wonosobo & 800 & 24 \\
\hline Dieng & 2100 & 16,25 \\
\hline
\end{tabular}

Sumber: rerata dari data primer April Mei 2011

Di wilayah Parangtritis yang sebagian besar wilayahnya berupa gisik (beach), terdiri dari bermacam-macam bukit pasir (sand dunes), temperatur udara pada siang hari jauh lebih panas dari pada malam hari. Berdasar data sekunder yang diperoleh dari rerata suhu udara sejak 1978 hingga 1987 dari Kretek dengan ketinggian sekitar 20 meter, dan data dari Barongan Jetis pada ketinggian 31 meter tahun 2001 - 2010, wilayah Parangtritis memiliki suhu udara rerata bulan Januari $27,8^{\circ} \mathrm{C}$, Februari $28,91^{\circ} \mathrm{C}$, Maret $27,96^{\circ} \mathrm{C}$, April $28,35^{\circ} \mathrm{C}$, Mei $28,04^{\circ} \mathrm{C}$, Juni $27,51^{\circ} \mathrm{C}$. Juli $27^{\circ} \mathrm{C}$, Agustus $27,34^{\circ} \mathrm{C}$, September $27,58^{\circ} \mathrm{C}$, Oktober $28,2^{\circ} \mathrm{C}$, November $28,14^{\circ} \mathrm{C}$, Desember $27,82^{\circ} \mathrm{C}$. Suhu udara rerata terendah jatuh pada bulan Juli dan Agustus, sedangkan suhu udara tertinggi pada bulan Februari Maret dan April, September, Oktober, dan November. Pada tahun 1978 suhu udara bulan April $27,8^{\circ} \mathrm{C}$, pada tahun 1987 telah naik menjadi $28,35^{\circ} \mathrm{C}$, dan rerata terakhir pada tahun 2001 - 2010 menjadi $27,91^{\circ} \mathrm{C}$. Namun demikian bila dihitung rerata tiga tahun terakhir (2008 - 2010) meningkat tajam menjadi $29,60^{\circ} \mathrm{C}$. Lihat tabel-tabel berikut.

Tabel 2. Temperatur udara rata-rata bulanan di daerah Kretek 1978-1987

\begin{tabular}{|l|l|l|l|l|l|l|l|l|l|l|l|}
\hline Tahun & 1978 & 1979 & 1980 & 1981 & 1982 & 1983 & 1984 & 1985 & 1986 & 1987 & Rerata \\
\cline { 1 - 11 } Bulan & & & & & & & & & & & \\
\hline Januari & 27,5 & 27,8 & 27,9 & 27,9 & 28 & 27,4 & 27,7 & 27,6 & 28,6 & 28,6 & 27,8 \\
\hline Februari & 27,1 & 27,8 & 28 & 27,7 & 28,6 & 27,9 & 27,9 & 27,8 & 27,9 & 28,4 & 28,91 \\
\hline Maret & 27,5 & 27,7 & 27,5 & 27,7 & 28,3 & 2784 & 27,9 & 28,5 & 27,8 & 28,9 & 27,96 \\
\hline April & 27,8 & 28,3 & 27,7 & 28,4 & 28,2 & 28,5 & 28,5 & 28,7 & 28,5 & 28,9 & 28,35 \\
\hline Mei & 27,9 & 27,8 & 27,5 & 28,5 & 28,4 & 27,7 & 28,1 & 28,3 & 28,3 & 27,9 & 28,04 \\
\hline Juni & 27,4 & 26,9 & 26,8 & 27,7 & 27,3 & 27 & 27,3 & 28,3 & 28,4 & 28 & 27,51 \\
\hline Juli & 27 & 27,2 & 25,4 & 26 & 26,6 & 26,1 & 29,7 & 27,6 & 27,2 & 27.2 & 27 \\
\hline Agustus & 27,4 & 27,4 & 27,1 & 26,2 & 26,9 & 26,5 & 27,5 & 29,2 & 28,6 & 27,6 & 27,34 \\
\hline Septembr & 27,9 & 28 & 27,1 & 25,3 & 26,7 & 27,7 & 27,7 & 28,6 & 28,4 & 28,4 & 27,58 \\
\hline Oktober & 27,4 & 27,6 & 28,7 & 28 & 27,8 & 28 & 28,5 & 29 & 28,5 & 28,5 & 28,2 \\
\hline Novembr & 27,7 & 27,7 & 27,5 & 29 & 29,7 & 28,8 & 28,1 & 27,3 & 27,8 & 27,8 & 28,14 \\
\hline Desembr & 27,6 & 27,6 & 27,7 & 27,8 & 27,5 & 27,8 & 27,9 & 27,9 & 28,2 & 28,2 & 27,82 \\
\hline
\end{tabular}

Sumber : (PT Awani Modern, 1997) 
Tabel 3. Temperatur udara rata-rata bulanan di Barongan Jetis

\begin{tabular}{|l|l|l|l|l|l|l|l|l|l|l|l|l|}
\hline Tahun & 2001 & 2002 & 2003 & 2004 & 2005 & 2006 & 2007 & 2008 & 2009 & 2010 & Rata08-1 & Rerata \\
\cline { 1 - 11 } Bulan & & & & & & & & & & & & \\
\hline Januari & 27,07 & 26,66 & 26,48 & 26,79 & 26,79 & 27,18 & 27,18 & 29,24 & 30,66 & 29,34 & 29,75 & 27,75 \\
\hline Februari & 26,07 & 27,01 & 27,03 & 26,41 & 26,56 & 27,26 & 27,26 & 29,13 & 29,69 & 28,41 & 29,07 & 27,50 \\
\hline Maret & 27,22 & 27,48 & 27,56 & 26,53 & 30,65 & 27,08 & 27,97 & 29,23 & 30,89 & 29,92 & 30,01 & 28,38 \\
\hline April & 27,72 & 27,77 & 27,86 & 27,50 & 26,77 & 28,5 & 28,7 & 29,21 & 30,12 & 30,25 & 29,86 & 28,44 \\
\hline Mei & 27,88 & 27,84 & 27,72 & 27,33 & 27,10 & 27,7 & 28,1 & 29,30 & 30,55 & 29,63 & 29,83 & 28,31 \\
\hline Juni & 27,21 & 27,54 & 26,60 & 26,19 & 26,82 & 27 & 27,3 & 29,31 & 31,10 & 30,55 & 30,32 & 27,95 \\
\hline Juli & 27,21 & 27,52 & 24,89 & 26,28 & 25,91 & 26,1 & 29,7 & 26,56 & 30,85 & 30,87 & 29,42 & 27,59 \\
\hline Agustus & 26,28 & 25,96 & 26,24 & 25,57 & 26,99 & 26,5 & 27,5 & 26,35 & 29,73 & 29,99 & 28,69 & 27,11 \\
\hline $\begin{array}{l}\text { Septemb } \\
\text { r }\end{array}$ & 27,46 & 26,59 & 26,57 & 26,37 & 26,78 & 27,7 & 27,7 & 25,85 & 30,55 & 30,27 & 28,89 & 27,59 \\
\hline Oktober & 27,40 & 27,43 & 27,31 & 27,06 & 26,96 & 28,45 & 28,5 & 26,96 & 30,29 & 30,37 & 29,21 & 28,08 \\
\hline Novembr & 27,06 & 27,83 & 26,09 & 26,42 & 27,28 & 28,14 & 28,27 & 30,05 & 30,32 & 30,00 & 30,12 & 28,14 \\
\hline Desembr & 26,62 & 26,29 & 26,39 & 27,8 & 26,75 & 27,46 & 29,16 & 30,03 & 30,02 & 30,00 & 30,01 & 28,03 \\
\hline Rerata & & & & & & & & & & & 29,60 & 27,91 \\
\hline
\end{tabular}

\section{Kondisi Curah Hujan}

Untuk membandingkan perubahan iklim dapat juga melihat kondisi curah hujan. Kondisi curah hujan di wilayah Parangtritis dan sekitarnya menurut data curah hujan yang ada di stasiun terdekat belum ada perubahan signifikan., yaitu di Kecamatan Pundong dan Kecamatan Jetis seperti ada pada Tabel 4 dan Tabel 5.

Tabel 4. Curah Hujan di Kecamatan Pundong

\begin{tabular}{|l|l|l|l|l|l|l|l|}
\cline { 1 - 7 } Tahun & 1989 & 1990 & 1991 & 1992 & 1993 & 1994 & 1995 \\
\cline { 1 - 6 } Bulan & 162 & 127 & 413 & 326 & 250 & 348 & 210 \\
\hline Januari & 504 & 199 & 479 & 205 & 136 & 501 & 708 \\
\hline Maret & 93 & 328 & 185 & 247 & 308 & 408 & 459 \\
\hline April & 122 & 117 & 212 & 334 & 86 & 155 & 46 \\
\hline Mei & 120 & 23 & 40 & 78 & 23 & 0 & 0 \\
\hline Juni & 49 & 25 & 2 & 19 & 18 & 0 & 0 \\
\hline Juli & 52 & 17 & 0 & 76 & 0 & 0 & 0 \\
\hline Agustus & 32 & 33 & 0 & 0 & 18 & 0 & 0 \\
\hline September & 2 & 0 & 0 & 28 & 0 & 0 & 0 \\
\hline Oktober & 63 & 29 & 0 & 226 & 0 & 2 & 69 \\
\hline November & 1563 & 160 & 144 & 233 & 113 & 51 & 511 \\
\hline Desember & 178 & 334 & 131 & 224 & 334 & 188 & 606 \\
\hline & 1533 & 1283 & 1606 & 1996 & 1286 & 1651 & 2609 \\
\hline
\end{tabular}

Sumber : Stasiun Meteorologi Pundong 
Tabel 5. Curah Hujan di Barongan Jetis

\begin{tabular}{|c|c|c|c|c|c|c|c|c|c|c|}
\hline Tahun & \multirow[t]{2}{*}{2001} & \multirow[t]{2}{*}{2002} & \multirow[t]{2}{*}{2003} & \multirow[t]{2}{*}{2004} & \multirow[t]{2}{*}{2005} & \multirow[t]{2}{*}{2006} & \multirow[t]{2}{*}{2007} & \multirow[t]{2}{*}{2008} & \multirow[t]{2}{*}{2009} & \multirow[t]{2}{*}{2010} \\
\hline Bulan & & & & & & & & & & \\
\hline Januari & 465 & 333 & 355 & 236 & 201 & 147 & 1877 & 89 & 278 & 61 \\
\hline Februari & 225 & 256 & 334 & 256 & 263 & 997 & 997 & 125 & 140 & 81 \\
\hline Maret & 277 & 156 & 225 & 309 & 472 & 2351 & 153 & 109 & 74 & 113 \\
\hline April & 55 & 100 & 5 & 31 & 0 & 687 & 74 & 68 & 73 & 70 \\
\hline Mei & 17 & 63 & 72 & 131 & 0 & - & 44 & 2 & 111 & 168 \\
\hline Juni & 0 & 0 & 16 & 3 & 180 & 0 & 79 & 0 & 0 & 32 \\
\hline Juli & 9 & 0 & 0 & 22 & 18 & 0 & 1 & 0 & 0 & 22 \\
\hline Agustus & 0 & 0 & 0 & 0 & 0 & 0 & 0 & 0 & 0 & 28 \\
\hline Septmbr & 0 & 0 & 0 & 0 & 0 & 0 & 1 & 0 & 0 & 94 \\
\hline Oktober & 191 & 0 & 40 & 16 & 293 & 4 & 16 & 105 & 9 & 75 \\
\hline Novemr & 256 & 104 & 271 & 282 & 294 & 0 & 77 & 134 & 39 & 110 \\
\hline Desembr & 216 & 334 & 420 & 588 & 709 & 683 & 225 & 133 & 40 & 300 \\
\hline Jumlah & & & & & & & & & & \\
\hline
\end{tabular}

Sumber : Stasiun Meteorologi Barongan Jetis

Schmith dan Ferguson menggolongkan tipe iklim berdasarkan curah hujan di Indonesia berdasarkan besar kecilnya nilai $\mathrm{Q}$. Penggolongan nilai $\mathrm{Q}$ didasarkan atas data curah hujan tahunan dari daerah penelitian. Pembagian iklim, menurut tipe curah hujan Schmid dan Ferguson adalah sebagai berikut:

Tabel 6. Pembagian Tipe Curah Hujan menurut Schmidt dan Ferguson

\begin{tabular}{|c|c|c|l|}
\hline Tipe & \multicolumn{1}{|c|}{ Bulan Kering } & \multicolumn{1}{|c|}{ Nilai Q } & \multicolumn{1}{|c|}{ Kondisi Iklim } \\
\hline A & $<1,5$ & $<0,14$ & Sangat Basah(Very Wet) \\
B & $1,5<3,0$ & $0,14<0,33$ & Basah(Wet) \\
C & $3,0<4,5$ & $0,33<, 60$ & Agak Basah(Fairly Wet) \\
D & $4,5<6,0$ & $0,60<1,00$ & Sedang(Fairly) \\
E & $6,0<7,5$ & $1,00<1,67$ & Agak Kering(FairlyDry) \\
F & $7,5<9,0$ & $1,67<3,00$ & Kering(Dry) \\
G & $9,0<10,5$ & $3,00<7,00$ & Sangat Kering (Very Dry) \\
H & $>10,5$ & $>7,00$ & Luar Biasa Kering(Extremely \\
& & & Dry) \\
\hline
\end{tabular}


Pada diagram dan grafik terlihat sebagai berikut:

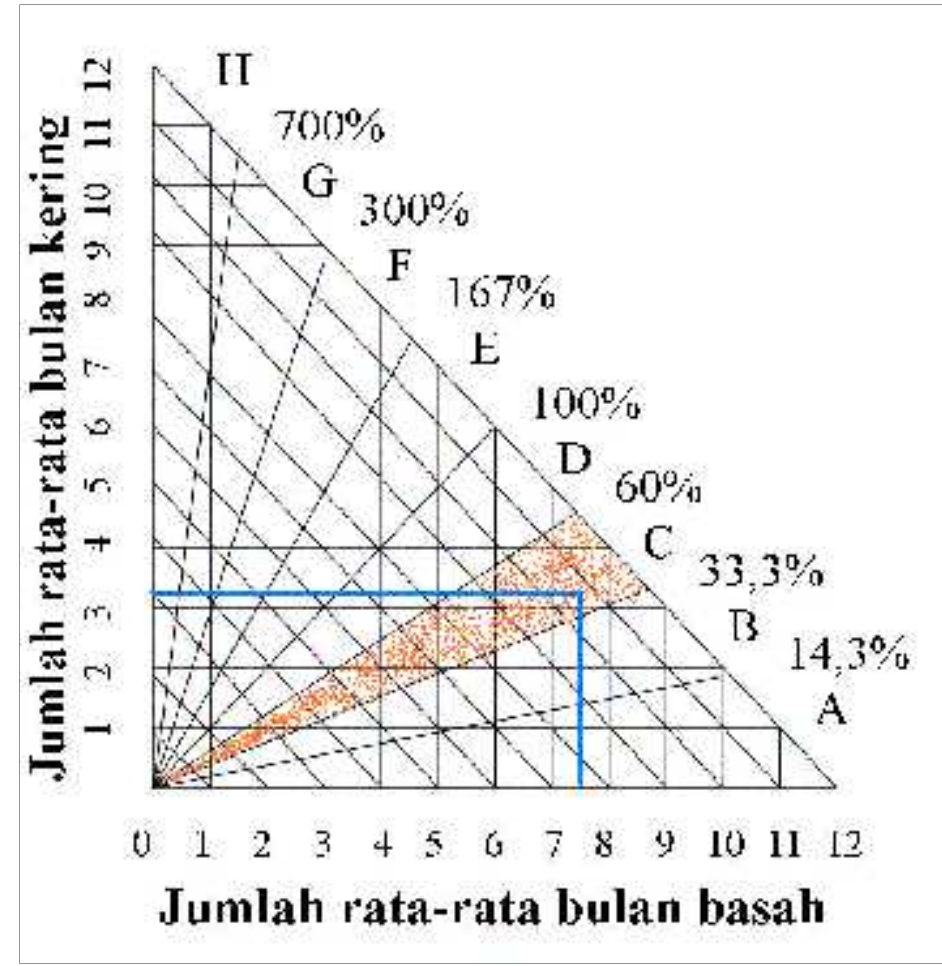

Gambar. Tipe Curah Hujan menurut Schmidt and Ferguson.

Koppen mengklasifikasikan iklim berdasarkan temperatur dan rata-rata curah hujan bulanan yang dihubungkan dengan keadaan vegetasi alami berdasarkan peta vegetasi. Menurut Koppen Vegetasi yang hidup secara alami menggambarkan iklim tempat tumbuhnya. Vegetasi itu tumbuh dan berkembang sesuai dengan hujan efektif yaitu kesetimbangan antara hujan, suhu, dan evapotranspirasi. Klasifikasi Koppen adalah sebagai berikut:

1. Iklim Hujan Tropika (Tropical Raining Climate/ A)

Golongan iklim yang mempunyai suhu bulan terdingin diatas $18^{\circ} \mathrm{C}$. Dengan curah hujan lebih besar daripada evapotranspirasi tahunan.

2. Iklim Kering (Dry Climate/ B)

Golongan iklim ini, curah hujan yang diterima lebih kecil dari penguapan.

3. Iklim Sedang (Humid Mesothermal Climate/ C)

Golongan iklim yang mempunyai suhu bulan terpanas diatas $10^{\circ} \mathrm{C}$ dan suhu bulan terdingin antara $0^{\circ} \mathrm{C}-18^{\circ} \mathrm{C}$.

4. Iklim Dingin (Humid Microthermal Climate/ D)

Golongan ini mempunyai temperature atau suhu rata-rata bulan terdingin kurang dari $0^{\circ} \mathrm{C}$ dan rata-rata bulan terpanas lebih besar daripada $10^{\circ} \mathrm{C}$

5. Iklim Kutub (Polar Climate/ E)

Rata-rata temperatur bulan terpanas kurang dari $10^{\circ} \mathrm{C}$

Selanjutnya Koppen membagi iklim Hujan Tropik (A) menjadi tiga tipe, yaitu :

a) Tipe Hutan Hujan Tropik (Af)

Ciri-ciri daerah yang termasuk tipe iklim ini adalah: temperatur bulan terdingin lebih besar dari $18^{\circ} \mathrm{C}$. Curah hujan rata-rata bulan terkering lebih besar dari $60 \mathrm{~mm}$. 
b) Iklim Monsun Tropis (Am)

Suatu daerah yang apabila curah hujan bulan terkering lebih kecil dari 2,4 inci $(60 \mathrm{~mm})$ dan lebih besar dari 3,94 - r/25 dengan keterangan $r$ adalah curah hujan tahunan dalam inci. Daerah Iklim Monsun Tropis ini pada bulan - bulan basah dapat mengimbangi kekeringan pada bulan kering dan pada umumnya masih terdapat hutan yang cukup lebat.

c) Iklim Savana (Aw)

Suatu daerah yang apabila curah hujan bulan terkering lebih kecil dari 3,94 - r/25 (Soekardi Wisnubroto, 1986 : 70).

Berdasarkan tipe iklim menurut Koppen, maka suatu daerah dapat dimasukkan ke dalam tipe iklim Am, Aw, atau Af.

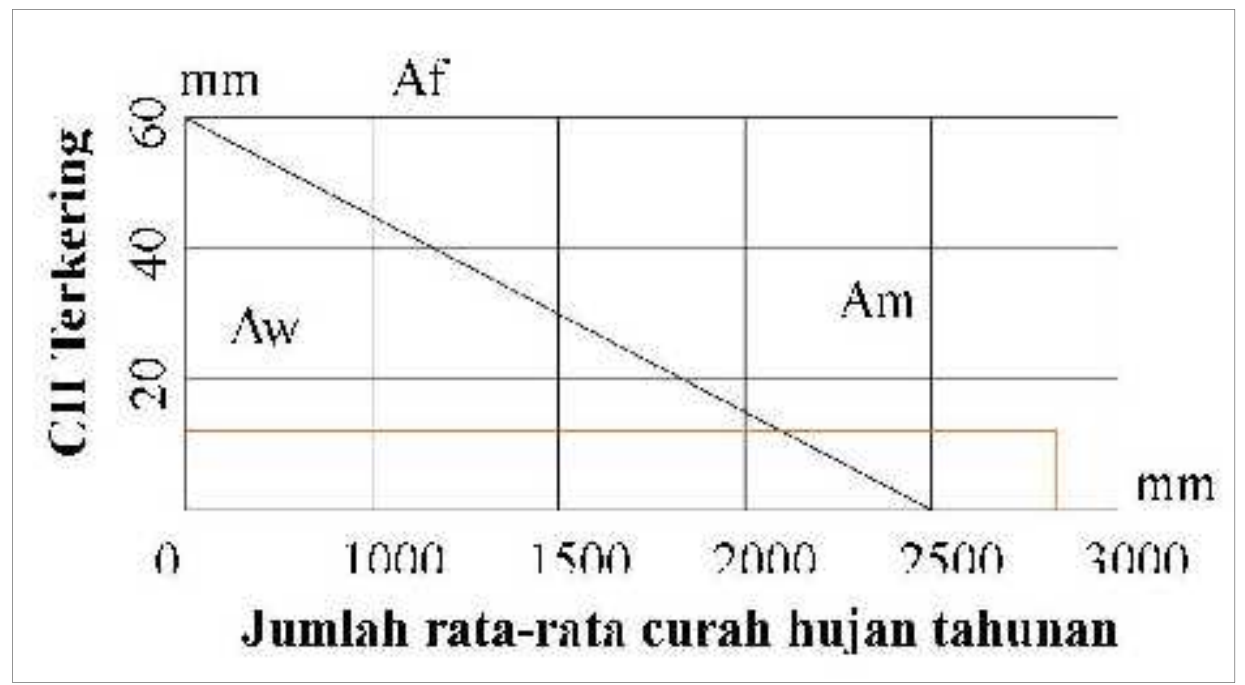

\section{Temperatur}

Gambar Tipe Iklim menurut Koppen

Data mengenai temperatur udara di wilayah daerah penelitian dapat diketahui dengan perhitungan matematika. Menurut Rumus Braak (Sandy, I Made (1987:8) Suhu rata-rata tahunan di permukaan daratan pada ketinggian 0 meter di atas permukaan air laut adalah $26,3^{\circ} \mathrm{C}$. Seterusnya setiap kenaikan 100 meter d.p.a.l., angka penurunan suhu adalah $0,6^{\circ} \mathrm{C}$. Berdasarkan data ketingggian, maka dengan menggunakan rumus Braak pada ketinggian 800 meter di wilayah Wonosobo seharusnya menjadi seperti berikut.

$\left(0,61^{\circ} \mathrm{C}\right) \mathrm{h}$

$\mathrm{t}=26,3^{\circ} \mathrm{C}$

100

$\left.\left(0,61^{\circ} \mathrm{C}\right) 800\right)$

$\mathrm{t}=26,3^{\circ} \mathrm{C}-100$

Namun demikian data terbaru menunjukkan bahwa temperatur rerata wilayah pantai yang mendekati 0 meter adalah $28,5^{\circ} \mathrm{C}$. Berdasarkan data temperature terbaru tersebut maka temperature pada ketingggian 800 meter di Wonosobo seharusnya seperti berikut. 
$\left.\left(0,61^{\circ} \mathrm{C}\right) 800\right)$

$$
\mathrm{t}=28,5^{\circ} \mathrm{C}-\mathrm{c}, 62^{\circ} \mathrm{C}
$$

Kenyataaan di lapangan suhu rerata yang diambil selama satu bulan dari 8 April hingga 8 Mei 2011 adalah $24^{\circ} \mathrm{C}$.

Bila diterapkan di wilayah lain dengan ketinggian 2100 meter di wilayah Dieng, hasilnya seperti berikut.

$\left(0,61^{\circ} \mathrm{C}\right) 2100$

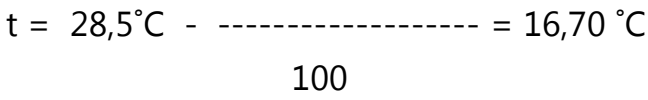

Kenyataaan di lapangan suhu rerata yang diambil selama satu bulan dari 8 April hingga 8 Mei 2011 adalah $16,25^{\circ} \mathrm{C}$.

Dengan asumsi formula Braak berdasarkan temperatur setempat pada 0 meter di atas permukaan air laut, maka sebenarnya rumus atau formula Braak tidak ada kesalahan yang signifikan. Pada ketinggian 800 meter di wilayah Wonosobo, perbedaan temperatur hasil perhitungan rumus Braak dengan data lapangan hanya $23,62{ }^{\circ} \mathrm{C}$ dengan $24{ }^{\circ} \mathrm{C}$, atau 1,2\%, sedangkan di wilayah dengaan ketinggian 2100 meter di wilayah Dieng ada perbedaan temperatur hasil perhitungan rumus Braak dengan data lapangan hanya 16,70 ${ }^{\circ} \mathrm{C}$ dengan $16,25{ }^{\circ} \mathrm{C}$, atau $2,1 \%$.

Hasil perhitungan tentu saja tidaklah sangat akurat, karena data yang digunakan hanya selama satu bulan. Temperatur diukur pada jam 7 jam 13.00 dan jam 18.00 .

\section{Penutup}

Perbedaan suhu udara berdasar perbedaan tinggi tempat masih mengikuti rumus Braak, hanya suhu udara di permukaan laut yang sering para peneliti menggunakan angka $26,3^{\circ} \mathrm{C}$, menjadi berubah, sangat variatif, namun berdasarkan data sepuluh tahun teraakhir aanghka meencapai $27,91^{\circ} \mathrm{C}$. Temperatur udara berdasarkan data menunjukkan bahwa terjadi peningkatan yang saangat nyata. Pada tahun 1978 di wilayah Parangtritis, suhu udara rerata masih berkisar $27^{\circ} \mathrm{C}$, pada tahun 1987 telah meningkat menjadi $28,3^{\circ} \mathrm{C}$, suhu udara rerata 2001-2010 sebesar 27,91, untuk rerata tiga tahun dari 2008 hingga 2010 telah mencapai $29,1^{\circ} \mathrm{C}$, dan pada tahun 2011 untuk rerata suhu udara diperoleh angka $28,5^{\circ} \mathrm{C}$. Wilayah pantai yang merupakan wakil permukaan air laut bersuhu udara $28,5^{\circ} \mathrm{C}$, suhu udara pada $800 \mathrm{~m}$ sebesar $24^{\circ} \mathrm{C}$, dan suhu udara pada ketinggiaan udara 2100 meter sebesar $16,25^{\circ} \mathrm{C}$. Pada ketinggian 800 meter, perbedaan temperatur hasil perhitungan rumus Braak dengan data lapangan hanya $23,62{ }^{\circ} \mathrm{C}$ dengan $24{ }^{\circ} \mathrm{C}$, atau $1,2 \%$, sedangkan di wilayah dengaan ketinggian 2100 meter, perbedaan temperatur hasil perhitungan rumus Braak dengan data lapangan hanya $16,70{ }^{\circ} \mathrm{C}$ dengan $16,25{ }^{\circ} \mathrm{C}$, atau $2,1 \%$. Perlu ada penelitian lebih rinci per wilayah dengan pengukuran suhu udara lebih akurat agar dapat menjadi pagu peneliti berikutnya. 


\section{DAFTAR PUSTAKA}

Bambang Irawan, 2006. Forum Penelitian Agronomi. Vol 24. No. 1 Juli 2006: 28-45.

Queenland Government, 2010. (Department of Environment and Resource Management)

Ray K. Linsley. JR; (1989). Hidrologi Untuk Insinyur Jakata: Erlangga

Schmidt and Ferguson. Meteotrology. New York : John Willey \& Sons

Strahler (1987), Modern Physical Geography, New York : John Willey \& Sons

Damen, M. C. J. 1989. Cities and Environmental Earth Sciences. Enschede: International Institute for Aerospace Survey and Earth Sciences, ITC.

Hansen, A. 1984. Landslide hazards Analysis. Geotechnical Control Office, London: University of London.

Huntington, E. Human Geography. London: John Willey \& Sons.

King, 1964. An Introduction to Oceanography. New York: McGraw Hill Book Company.

Sahala Hutabarat, 1982. Pengantar Oseanografi. Jakarta: UI Press.

PT. Awani Modern, 1997. Laporan Analisis Dampak Lingkungan, Pengembangan Kawasan Pariwisata Parangtritis. Yogyakarta: CV Pamor Keris.

Verstappen, H. Th., 1985. Applied Geomorphological Survey and Natural Hazard Zoning. Enschede: ITC.

Warta Indonesia, 14 Mei 2010. Dampak El Nino: cuaca Ekstrem Bakal landa Indonesia 